Historic, Archive Document

Do not assume content reflects current scientific knowledge, policies, or practices. 



\section{Craig Specialties SPRING PRICE LIST 1927 Craig Specialties EASTER AND SPRING DELIVERY}

Never before have we offered to our customers such a complete line of stock and of such high quality, including both Flowering and Foliage Plants. We are booking

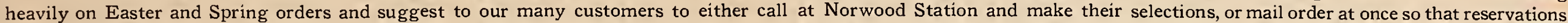
can be made to avoid dite

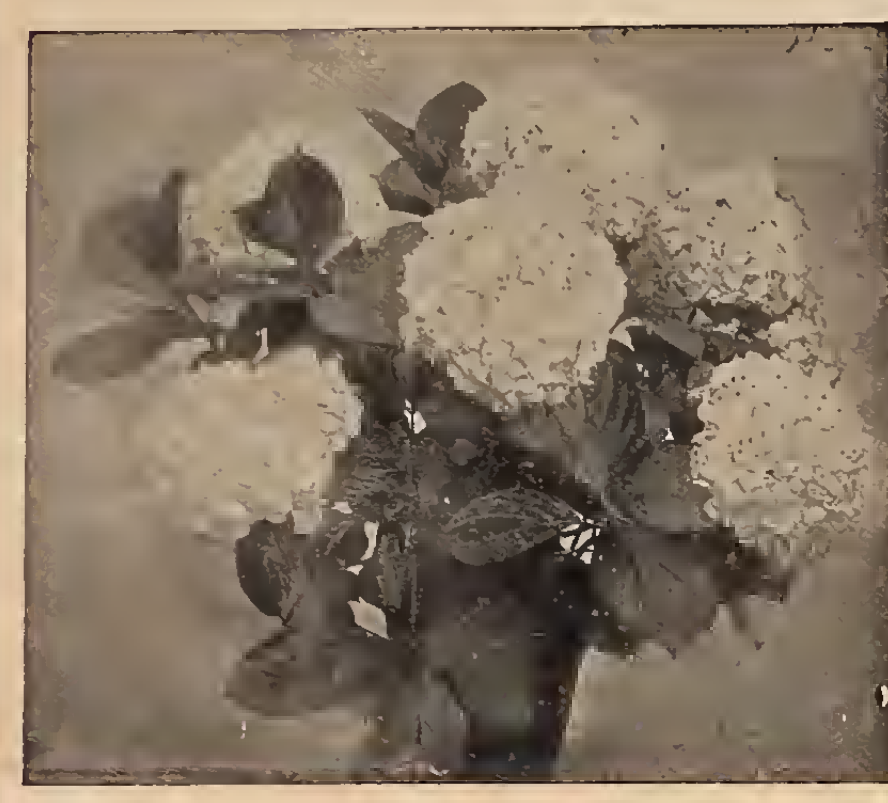

HYDRANGEAS

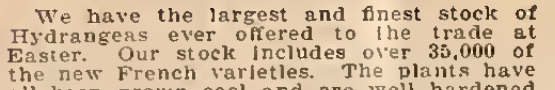

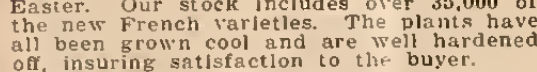

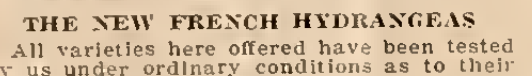

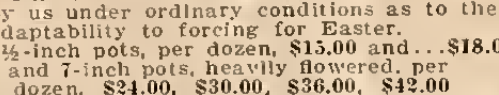

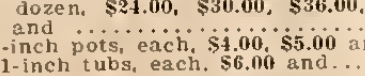
ROSES

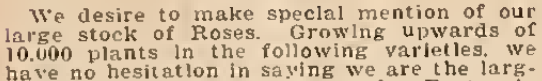

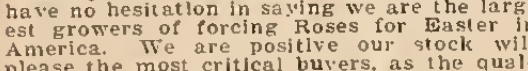

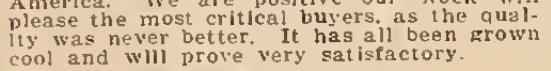
DOROTHX PERKINS

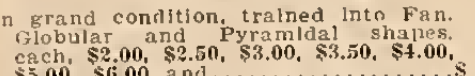

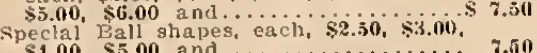

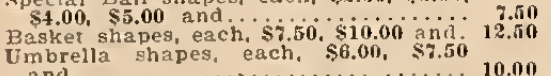

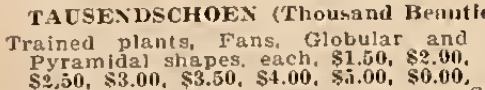

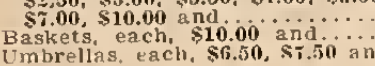
ROBERT CRAIG COMPANY,
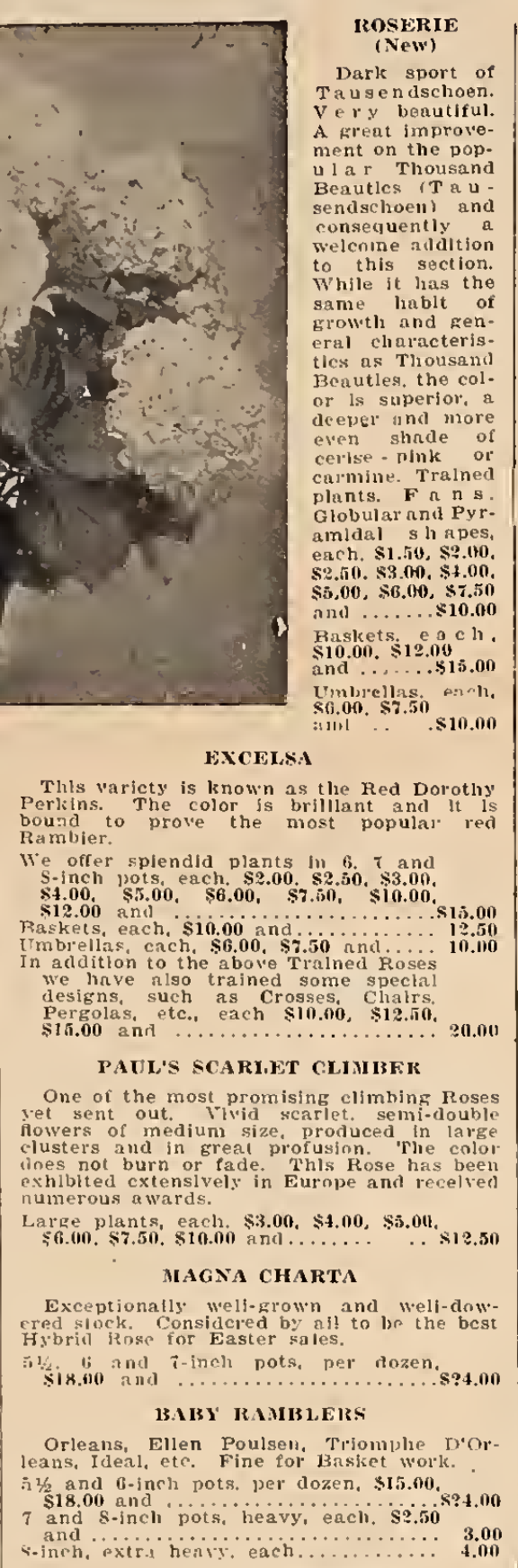

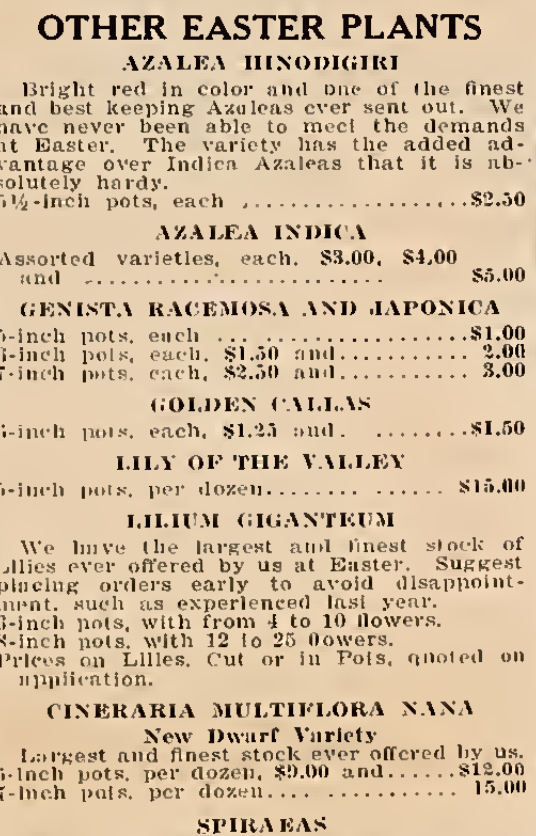

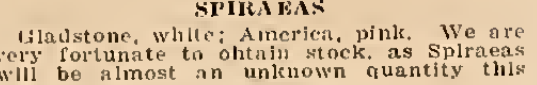

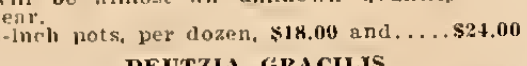

DEVTTZL GRACLIS
bi-inelo pots, per dozen
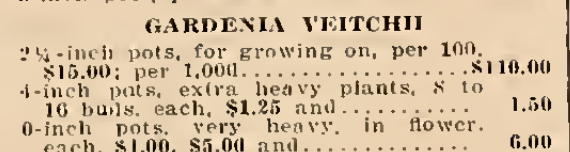

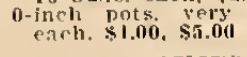

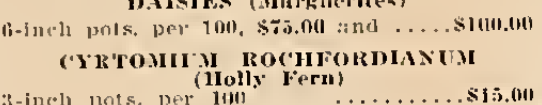

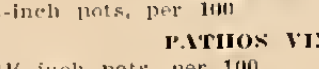

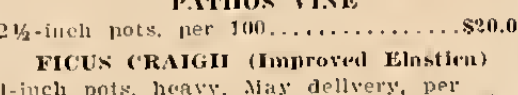

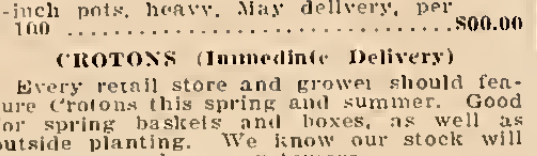

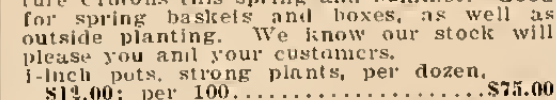

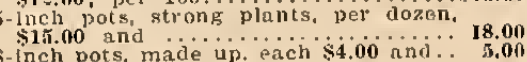

croton PUNCTATa

the finest watctata

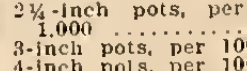

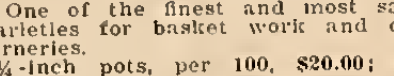

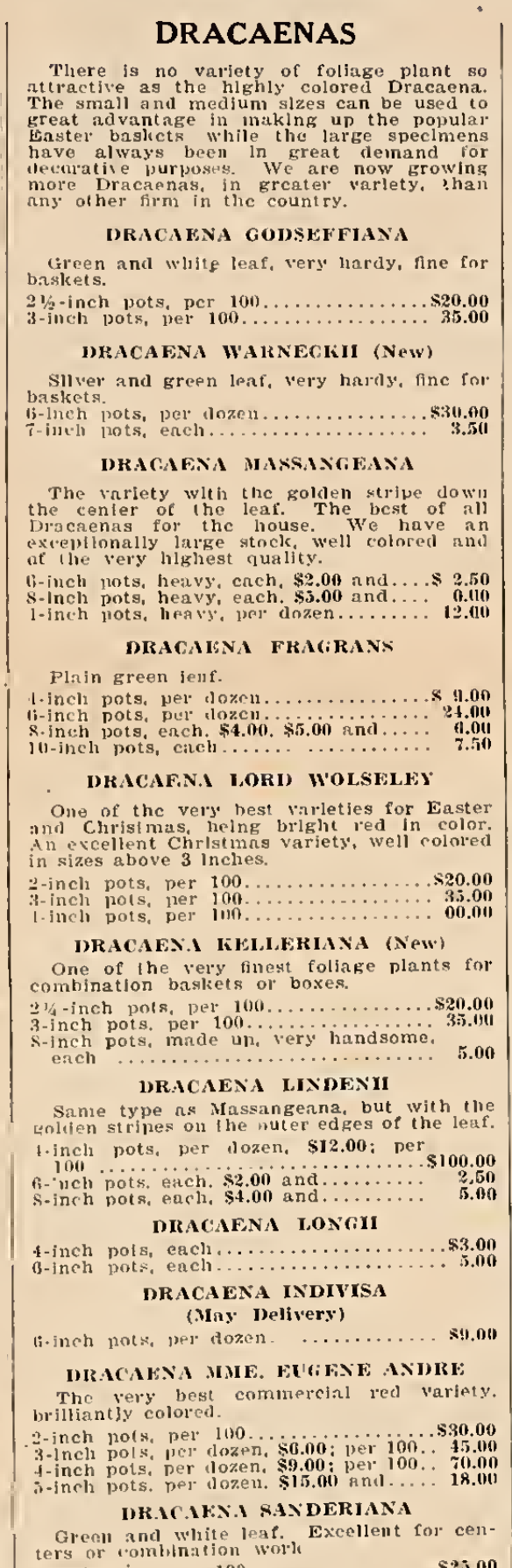

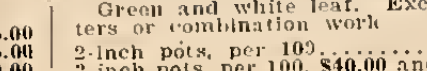

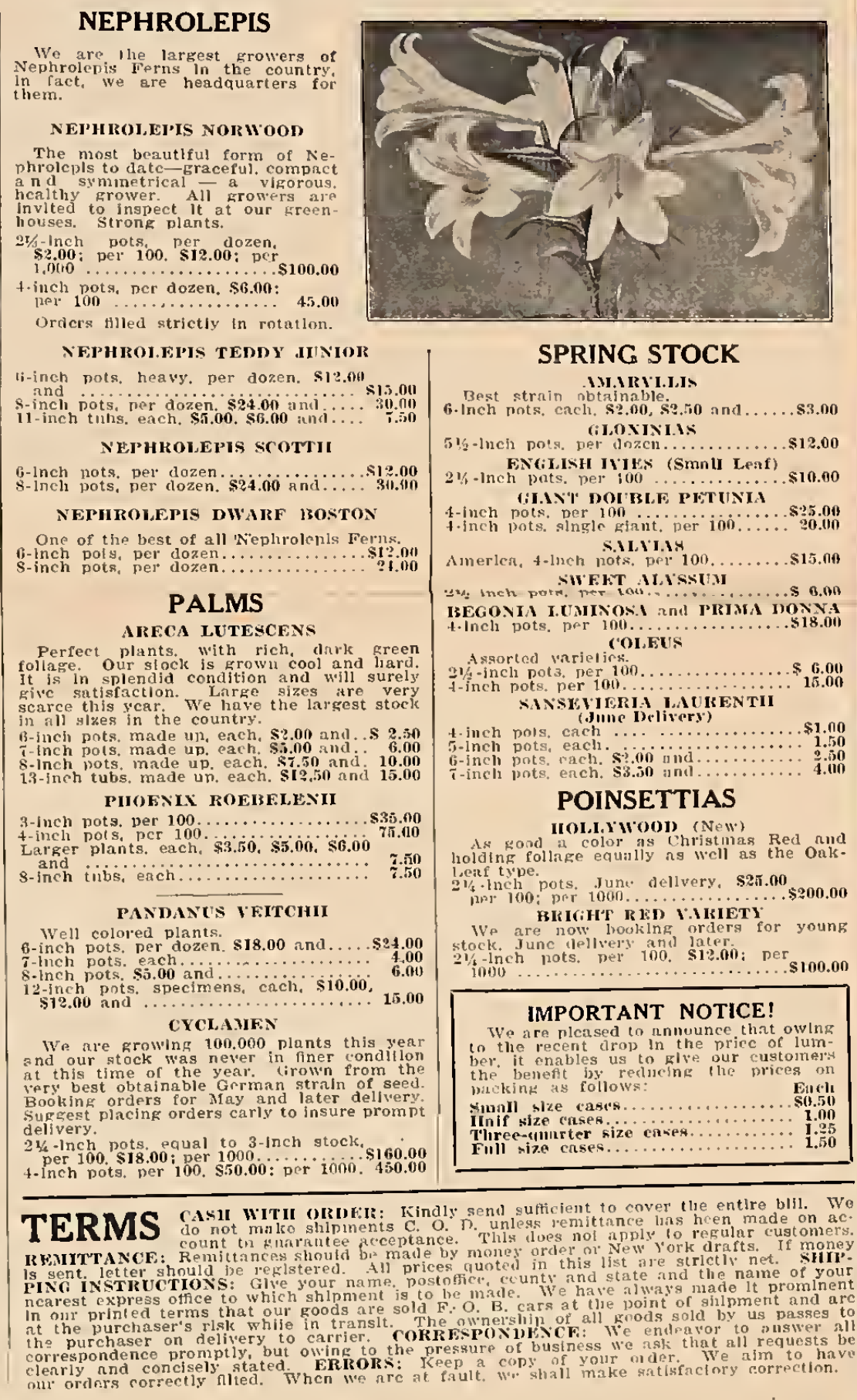

Station, Delaware County, $\mathrm{Pa}$ 
